\title{
Comparison of evapotranspiration components and water-use efficiency among different land use patterns of temperate steppe in the Northern China pastoral-farming ecotone
}

\author{
Yuzhe $\mathrm{Li}^{1,2}$ - Jiangwen $\mathrm{Fan}^{1} \cdot{\text { Zhongmin } \mathrm{Hu}^{3} \text { - Quanqin Shao }}^{1}$ - Warwick Harris ${ }^{4}$
}

Received: 26 November 2014 / Revised: 18 September 2015 /Accepted: 27 September 2015 /Published online: 8 October 2015

(C) ISB 2015

\begin{abstract}
Water-use efficiency (WUE), which links carbon and water cycles, is an important indicator of assessing the interactions between ecosystems and regional climate. Using chamber methods with and without plant removal treatments, we investigated WUE and evapotranspiration (ET) components in three ecosystems with different land-use types in Northern China pastoral-farming ecotone. In comparison, ET of the ecosystems with grazing exclusion and cultivating was 6.7 and $13.4 \%$ higher than that of the ecosystem with free grazing. The difference in ET was primarily due to the different magnitudes of soil water evaporation (E) rather than canopy transpiration (T). Canopy WUE (WUEc, i.e., the ratio of gross primary productivity to $\mathrm{T}$ ) at the grazing excluded and cultivated sites was 17 and $36 \%$ higher than that at the grazing site. Ecosystem WUE (WUEnep, i.e., the ratio of net ecosystem productivity to ET) at the cultivated site was 34 and $28 \%$ lower in comparison with grazed and grazing excluded stepped, respectively. The varied leaf area index (LAI) of different land uses was
\end{abstract}

Yuzhe Li

liyz.12b@igsnrr.ac.cn

Jiangwen Fan

fanjw@igsnrr.ac.cn

1 Key Laboratory of Land Surface Pattern and Simulation, Institute of Geographical Sciences and Natural Resources Research, Chinese Academy of Sciences, Beijing 100101, China

2 Graduate University of Chinese Academy of Sciences, Beijing 100049, China

3 Key laboratory of Ecosystem Network Observation and Modeling, Synthesis Research Center of Chinese Ecosystem Research Network, Institute of Geographic Sciences and Natural Resources Research, Chinese Academy of Sciences, Beijing 100101, China

4 Landcare Research, PO Box 69040, Lincoln 7640, New Zealand correlated with microclimate and ecosystem vapor/carbon exchange. The LAI changing with land uses should be the primary regulation of grassland WUE. These findings facilitate the mechanistic understanding of carbon-water relationships at canopy and ecosystem levels and projection of the effects of land-use change on regional climate and productivity.

Keywords Temperate steppe · Evapotranspiration composition · Water-use efficiency · Pastoral-farming ecotone $\cdot$ Grassland use change $\cdot$ Grassland cultivation . Grazing exclusion
Abbreviation
Land uses
G Grazed steppe
GE Grazing exclusion steppe
C Steppe cultivated to cropland
Treatments
DS Sprayed with herbicide, its plant cover was dead and dry
CL Plants was clipped to ground and removed
CK Control plot without any treatments
Ecosystem fluxes
E Evaporation
T Transpiration
I Interception evaporation
ET Evapotranspiration
NEE Net ecosystem exchange
NEP Net ecosystem productivity
GEP Gross ecosystem productivity
$\mathrm{Re} \quad$ Ecosystem respiration
Water use efficiency
WUE Water use efficiency
WUEc Canopy water use efficiency, calculated as GEP/T 
WUEnee Instantaneous ecosystem water use efficiency, the ratio of NEE to ET

WUEnep Ecosystem water use efficiency, the ratio of NEP to ET

WUEgep Ecosystem water use efficiency, the ratio of GEP to ET

\section{Others}

AT Air temperature

ST Soil temperature

SM Soil moisture

$\mathrm{Rn} \quad$ Net radiation

VPD Vapor pressure deficit

LAI Leaf area index

\section{Introduction}

Water use efficiency (WUE), the ratio of $\mathrm{CO}_{2}$ assimilation to water losses, links water and carbon cycling together. It is an important and inherent ecosystem characteristic related to ecosystem productivity and carbon sink function (Beer et al. 2009; Keenan et al. 2013). WUE change may greatly impact on both ecosystem carbon and water budgets. Thus, more accurate and deeper understanding of the dynamics of WUE at various observation scales is conducive to the verification and improvement of the accuracy of assessment of regional mass and energy budgets (Hu et al. 2008). In arid and semiarid areas, water supply is a critical limiting factor of ecosystem productivity (Bai et al. 2008). Consequently, variation and composition of ecosystem vapor losses play an important role in shaping WUE and regional environmental conditions of these ecologically fragile areas (Bremer et al. 2001).

The grassland ecosystem, one of the most widespread arid and semiarid vegetation forms, occupies $20 \%$ of the global terrestrial area and plays an important role in the global carbon cycle (Scurlock and Hall 1998), water cycle (Hu et al. 2009), and energy balance (Chen et al. 2009a). China has the second largest area of grassland in the world covering 3.92 million $\mathrm{km}^{2}$ or about $16.3 \%$ of the global grassland area (Fan et al. 2008). In recent years, in order to reduce the frequency and intensity of dust storms, the Chinese government has made increased efforts to restore steppe grassland. Many critical steppe areas have been fenced and protected from grazing to promote their recovery (Liu et al. 2015). Conversely, for economic purposes and the need of food security, a large area of steppe in China has been converted to cropland (Miao et al. 2009). From 1990 to 2000, the cultivated area in the pastoralfarming ecotone increased by more than $1000 \mathrm{~km}^{2}$ (Liu et al. 2003). The large area of steppe use change may have greatly modified the regional carbon budget and water balance (Bremer et al. 2001). Therefore, possible changes of WUE in northern China steppe caused by land use changes may significantly influence regional environment conditions and even global climates and therefore be of concern to the welfare of humanity (Hall and Scurlock 1991; Scurlock and Hall 1998). However, little is known about how WUE responds to land use changes in the pastoral-farming ecotone, thus limiting accurate assessment of land use policy effects on the environment of northern China.

Previous studies have intensively analyzed how vegetation types and various environmental factors influence WUE at different spatial-temporal scales (Niu et al. 2008; Xu et al. 2013). By focusing on WUE regulated by changing environmental factors, these studies have greatly increased our understanding of the impact of potential climatic and vegetation changes on ecosystem functions (Beer et al. 2009; Keenan et al. 2013). Managing land use change is an important way for humans to mitigate the effects of and adapt to ongoing climate change. Land use change may significantly affect ecosystem WUE by changing ecosystem carbon and water budgets (Fisher et al. 2008) and consequently have impact on regional and global climates. There has been limited research on land use pattern effects on grassland ecosystem WUE (Brümmer et al. 2012). Therefore, understanding ecosystem WUE and its key controlling processes in response to land use change is helpful for more accurately predicting future ecosystem functions, including regional primary productivity, carbon storage, and water balance.

Though various controlling factors of WUE have been widely discussed in previous studies (Fisher et al. 2008; Xu et al. 2013), consensus lacked the conclusions on critical factors and regulation trends (Lauenroth et al. 2000; Li et al. 2008). The divergences might mainly be attributed to different calculation methods and scales of research (Lauenroth et al. 2000). Additionally, the feedbacks that determined complexity of the ecosystem mass exchange components involved in calculation may enhance this complexity (Béziat et al. 2013). Canopy transpiration (T) and total ecosystem evapotranspiration (ET) are two of the most frequently applied vapor consumptions in calculating WUE. In arid and semiarid ecosystems (e.g., temperate steppe), $\mathrm{T}$ is largely different from ET in general. The dry and hydropenic climate and low vegetation cover there increase the contribution of evaporation (E) in total water consumption (Luo et al. 2008; Bai et al. 2010). Consequently, it is necessary to separate $\mathrm{T}$ from ET accurately and reliably ( $\mathrm{Hu}$ et al. 2009; Béziat et al. 2013), when assessing WUE and its controlling mechanism in these special regions. Net ecosystem exchange (NEE) reveals net $\mathrm{CO}_{2}$ exchange at ecosystem level, and gross ecosystem productivity (GEP) could estimate the potential carbon absorption ability of canopy photosynthesis (Chen et al. 2009b). The gap between NEE and GEP depends on the ecosystem respiration (Re) level. GEP and Re are two of the inherent ecosystem traits that are complexly influenced by various meteorological factors and species characteristics (Hall and Scurlock 1991; Yepez et al. 2007). Because of the complex feedbacks 
between water balance and carbon budget and the difficulty in the accurate dividing of ecosystem mass fluxes (Kool et al. 2014), limited attempt has been made to compare different calculation methods in estimating WUE responding to land use differences. Thus, a proper ecosystem mass fluxes divide method will largely prompt our mechanism understanding on WUE regulation process.

In this study, we endeavored to divide ecosystem ET into canopy $\mathrm{T}$ and surface $\mathrm{E}$ more accurately than by the previously applied method of clipping and removing vegetation. This involved application of a technique that killed the vegetation by application of herbicide and leaving it standing to largely maintain the original shading situation. With novel treatment, we used chamber method to measure carbon-vapor fluxes in three typical land uses of local steppe. These use patterns were (1) grazed steppe, (2) steppe spelled from grazing, and (3) steppe cultivated for cropping. The three uses of steppe were located in adjoining areas of typical Inner Mongolia Stipa steppe. Using these manipulative methods, our study investigated the response of WUE at canopy and ecosystem levels to the changes of use of grassland steppe, and the factors driving their diurnal dynamics based on 1-h interval field observation during 12 days. Observation days were distributed alternatively among the three different land uses of steppe.

Specifically, we addressed the following questions. (1) How do the components of ET respond to different uses of Stipa steppe and what are the underlying factors driving these responses? (2) How does canopy and ecosystem WUE respond to the changes in community characteristics and microclimate factors influenced by different steppe use? (3) How are the diurnal dynamics of canopy and ecosystem WUE driven by changes of environmental factors?

\section{Methods}

\section{Site description}

The study was conducted on typical Stipa grandis-dominant temperate steppe $\left(43^{\circ} 32^{\prime} 24.06^{\prime \prime} \mathrm{N}, 116^{\circ} 33^{\prime} 41.76^{\prime \prime}\right.$ E, elevation $1250 \mathrm{~m}$ ) at Xilinhot, Inner Mongolia, northern China (Fig. 1). From local climate data (1982-2004), the mean annual temperature is $0.6^{\circ} \mathrm{C}$ and the mean monthly temperature ranges from $-21.4{ }^{\circ} \mathrm{C}$ (January) to $18.5^{\circ} \mathrm{C}$ (July). Mean annual precipitation is $350 \mathrm{~mm}$, mainly falling from June to August, coinciding with the main growth period. According to the main meteorological factors shown in Fig. 2, the mean air temperature was $16.5{ }^{\circ} \mathrm{C}$ during the experimental period. The peak growing month (August) in steppe area is the second warmest month of a year. The accumulated precipitation in this period was $80.6 \mathrm{~mm}$, and this value contributed more than one fourth of the annual precipitation.
According to the Chinese classification, soils of the study site are chestnut or chernozem soil (Chen et al. 2009b). Xilinhot is located at the northern edge of the Chinese pastoral-farming ecotone (Miao et al. 2009; Wu et al. 2013), where grazing is the primary land use. There are two alternative land uses of the steppe in the region as well. The first is exemplified by the Hunshandake desert located to the south of Xilinhot, which is known as an important source of sand for sandstorms affecting Beijing. With the aim of improving the environmental condition of Beijing, the central government has launched a series of grassland restoration projects to reduce and even remove grazing in the region of Xilinhot (Zhang et al. 2014) to curb sandstorms. By contrast, for some areas of the region where the local environment is considered to be suitable for cropping, economic considerations have resulted in cultivation of the steppe for crop production.

Land uses of grazed steppe $(\mathrm{G})$, grazing exclusion steppe (GE), and steppe cultivated to cropland (C) located adjacent to each other were selected for the study. With a large number of acronyms used, an abbreviation list was summarized for clarity. $G$ is a typical steppe that has been grazed by sheep and horses for more than 20 years. GE is steppe where grazing has been excluded since 1979 and where a large amount of litter remains on the ground. The original land use and the community structure of $\mathrm{C}$ were similar to $G$ until 5 years before the study when the land was cultivated for wheat cropping. No irrigation is applied to the cropped area. Organic manure was applied before the crop was planted, and $240 \mathrm{~kg} / \mathrm{hm}^{2}$ inorganic fertilizer (N $\left.110 \mathrm{~kg} / \mathrm{ha}, \mathrm{P}_{2} \mathrm{O}_{5} 70 \mathrm{~kg} / \mathrm{ha}, \mathrm{K}_{2} \mathrm{O} 60 \mathrm{~kg} / \mathrm{ha}\right)$ was applied in two applications during crop growth. In the central area of grazing steppe $\left(43^{\circ} 32^{\prime} 24.06^{\prime \prime} \mathrm{N}, 116^{\circ}\right.$ $33^{\prime} 41.76^{\prime \prime} \mathrm{E}$ ), one eddy covariance system was installed in 2011 to continuously measure the vapor and carbon exchange of the grazing ecosystem. The distance of the eddy covariance system from the boundaries of GE or C was about $800 \mathrm{~m}$. The 30 -min mean carbon flux, also the latent heat flux recorded, was standard-corrected and processed to NEE and ET rates (Hu et al. 2009) for comparison with the portable infrared method we used that is described below.

\section{Observational design}

A randomized block design with a total of 48 plots was used. Within each land use pattern, there were four replicate blocks ( $3.5 \mathrm{~m} \times 3.5 \mathrm{~m}, 5-\mathrm{m}$ space between blocks). In each block, four $1 \mathrm{~m} \times 1 \mathrm{~m}$ plots were randomly arranged with a space of $1.5 \mathrm{~m}$ between plots. Two weeks before the observation, one plot (DS) in each block was randomly selected and sprayed with herbicide (41\% glyphosate, water diluted 150 times). All the plants in this plot withered in 2 days, and the canopy of this treatment was kept standing and dry for the observation 
Fig. 1 The location of the study area and the pastoral-farming ecotone in North China

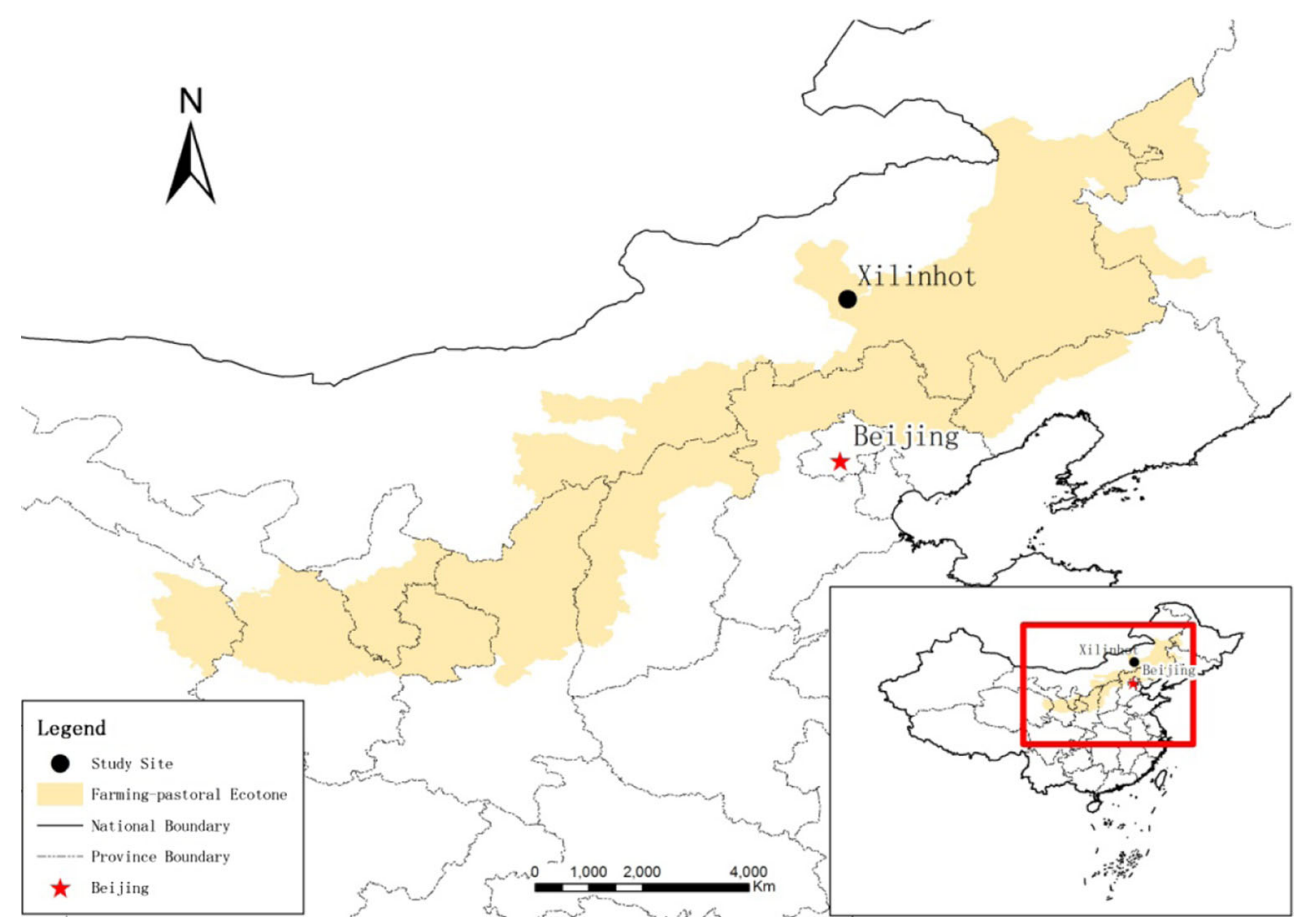

period. The aboveground tissue of another plot (CL) in each block was removed by clipping following the procedure used in previous studies (Chen et al. 2009b; Niu et al. 2011). The third plot was the control plot (CK) without any treatment. The fourth plot was used for destructive sampling to determine the community characteristics of the block including aboveground/belowground biomass, leaf area index (LAI), and soil properties. For more clarity, the treatments in all the three land uses are shown in Fig. 3.

\section{Community characteristics and biomass composition}

Percent cover of each species and the entirely vegetation cover were visually estimated in destructive sampling plots of each block with a $1 \mathrm{~m} \times 1 \mathrm{~m}$ gridded quadrats frame. Afterward, the aboveground biomass of each species in each destructive sampling plot was clipped to ground level, and the living fraction separated. Litter was collected without distinguishing species. The $0-30-\mathrm{cm}$ belowground biomass was sampled with root
Fig. 2 Daily precipitation, air temperature $(A T)$, and mean net radiation $(R n)$ during the experimental period from 1 August to 31 August, 2012, in a typical temperate steppe at Xilinhot, Inner Mongolia. Data were obtained from the eddy covariance system located in the center of grazed grassland

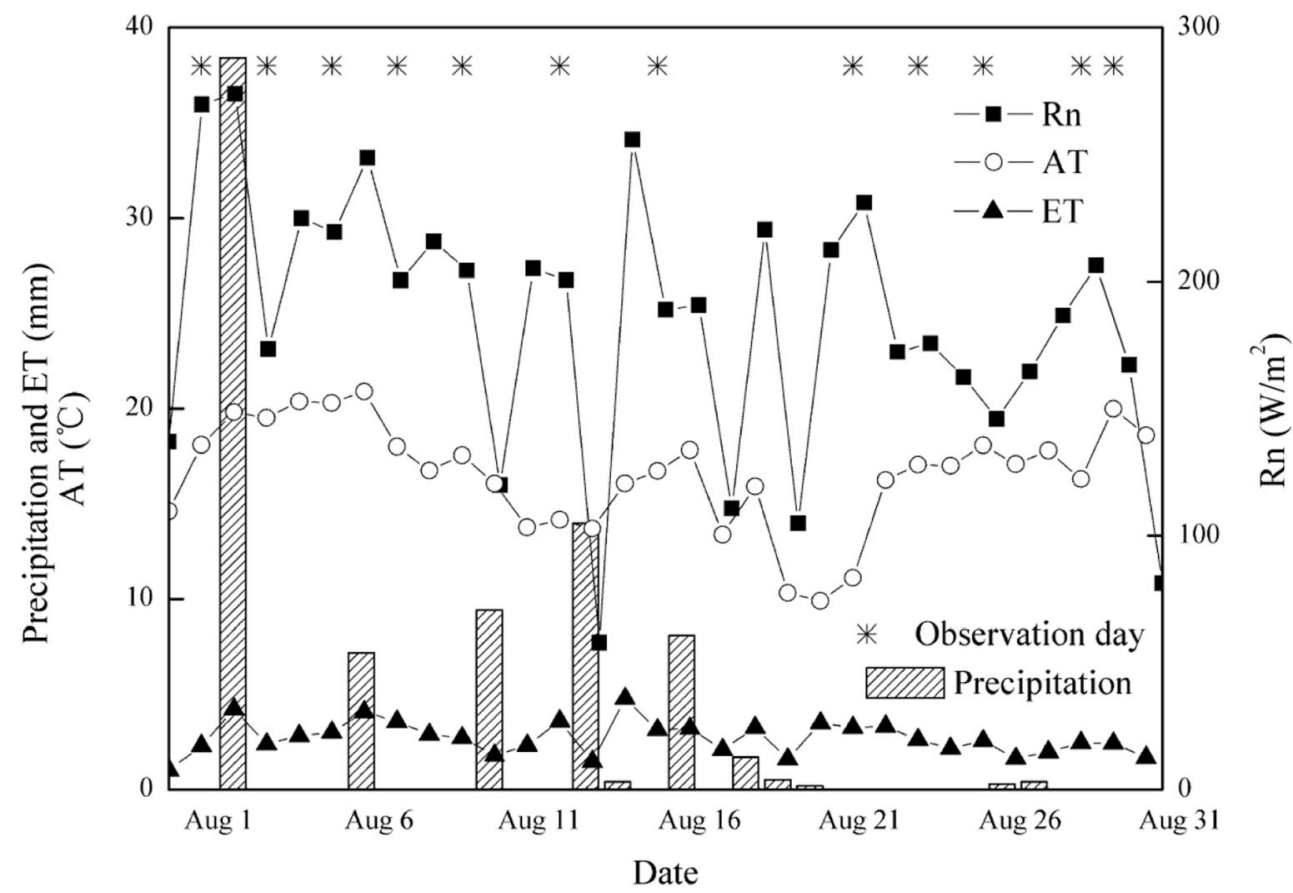


Fig. 3 Treatments of the three land-use types (a-c) plots with clipping (a), herbicide (b), and control (c) at the grazing site. $\mathbf{d}-\mathbf{f}$ plots with clipping (d), herbicide (e), and control (f) at the grazing exclusion site. $\mathbf{g}-\mathbf{i}$ plots with clipping (g), herbicide (h), and control (i) at the cropland site
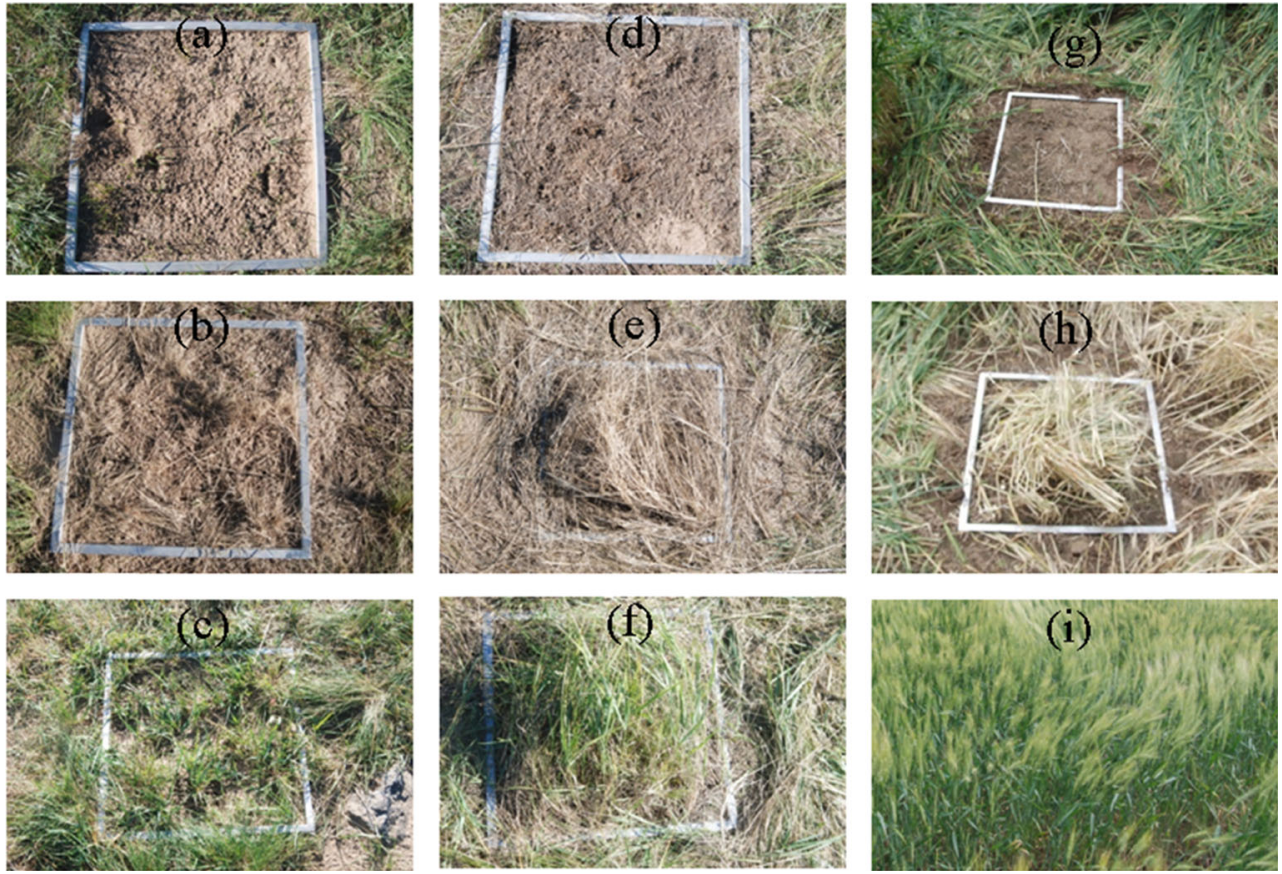

drill method, which was described in previous research (Fan et al. 2008). Before measuring the aboveground biomass, leaves were separated and their area was determined with a planimeter (LI-3000, Li-Cor, Lincoln, USA). All the aboveground biomass (leaves and non-leaf part) and belowground biomass were oven-dried at $70{ }^{\circ} \mathrm{C}$ for $48 \mathrm{~h}$ and weighed.

\section{Flux measurements}

Two weeks before the observations, a square metal base rim $(50 \mathrm{~cm} \times 50 \mathrm{~cm}$ in area, $10 \mathrm{~cm}$ in height with $3 \mathrm{~cm}$ left aboveground) was installed in each observed plot (CK, CL and DS), for the measurements of the components of canopy/ecosystem WUE. The vapor and carbon exchange rate of ecosystems or earth surfaces was measured by a cubic chamber $(50 \mathrm{~cm} \times$ $50 \mathrm{~cm} \times 50 \mathrm{~cm}$ ) attached to an infrared gas analyzer (IRGA; LI-6400, LiCor, Lincoln, NE, USA) (Niu et al. 2011). Two small fans were fixed inside the top of the chamber to mix air during measurement. One temperature probe was inserted inside the chamber to record air temperature (AT), and another was inserted into the surrounding earth at the depth of $5 \mathrm{~cm}$ to determine soil temperature (ST). The soil moisture (SM) content $(0-10 \mathrm{~cm})$ was simultaneously measured using a portable soil moisture device (TDR100, Spectrum, Plainfield, IL, USA). During the measurements, the transparent chamber was put on the metal base rim, and two rings of seal pads were installed on the bottom edge of the chamber to prevent leakage from the chamber. When measurements commenced, 30 consecutive recordings of $\mathrm{CO}_{2}$ and vapor concentrations were taken for each placed chamber at 1 -s intervals during 30 -s periods. $\mathrm{CO}_{2}$ and $\mathrm{H}_{2} \mathrm{O}$ flux rates were calculated from the time courses of changing concentrations. The fluxes of evaporation were directly determined in the treatments of DS, and evapotranspiration and NEE were determined in CK. Details about these static-chamber flux calculations can be found in the calculation procedure in the LI-6400 manual (LiCor Inc. 2004). This static-chamber method has been used and validated in previous studies (Huxman et al. 2004; Niu et al. 2011). Following measurement of NEE in CK treatments, the chamber was vented, replaced on each frame, and covered with an opaque cloth. Then, the $\mathrm{CO}_{2}$ exchange measurements were repeated, with light (and hence photosynthesis) eliminated, to obtain values representing ecosystem respiration (Niu et al. 2011, 2013). The difference between NEE and Re was considered to represent instantaneous GEP for the ecosystem within the chamber.

Measurements were conducted on clear sunny days at the peak of standing live grassland biomass (August). The observations were conducted continuously through the day at $1-\mathrm{h}$ intervals. In total, there were 12 observation days providing 4 days for each land use as replicates (Fig. 2). All the four blocks in one land use were observed on each observation day. The observation days were distributed alternatively among different ecosystems to enhance the comparability of data measured in similar weather conditions. ET, NEE, and Re were determined in control plots using standard methods (Chen et al. 2009b; Niu et al. 2013).

For determination of ET, compared with the clipping method (CL) used previously (Niu et al. 2008; Niu et al. 2011), our herbicide method (DS) provided more similar shading and surface roughness conditions to that of the control plots (CK), providing more realistic evaporation and microclimate conditions (Table 2). This DS method provides a more 
accurate determination of ecosystem E, thus improving the reliability of separating T from ET. Our method assumed that transpiration in the herbicide sprayed DS plots was completely suppressed by withering of all living plant tissue. Thus, vapor exchange in DS would mainly come from earth surface evaporation. Then canopy transpiration could be determined by the difference of vapor exchange rate between the CK and DS plots. Among different partitioning methods (reviewed by Kool et al. 2014), our approach should be a more accurate observation method to separate the components of $\mathrm{E}$ and $\mathrm{T}$ from ecosystem ET as it involves less disturbance of the original environmental conditions and avoids the influence of air advection or large eddies.

ET is academically divided into evaporation and transpiration. However, in previous applications (Fisher et al. 2008), most modeling research considered ET into three compositions. Besides canopy transpiration (T), the evaporation are split into two sources, soil evaporation (Es) and interception evaporation (I):

$\mathrm{ET}=\mathrm{T}+\mathrm{Es}+\mathrm{I}$

The climate in Inner Mongolia is dry and rainless. Additionally, the chamber determination was only applied in sunny meteorological condition. The contribution of interception evaporation should be at a very low level. Thus, the evaporation should be primarily contributed by soil evaporation. Consequently, by ignoring I, we calculated $\mathrm{T}$ from the difference of ET and E:

$\mathrm{T}=\mathrm{ETE}-\mathrm{E}$

GEP was calculated by the sum of NEE and Re:

$\mathrm{GEP}=-\mathrm{Re}+\mathrm{NEE}$

Net ecosystem productivity (NEP) is daily ecosystem primary productivity accumulated from NEE. Daily carbon (daily NEP, Re, and GEP) and water (E, T, and ET) exchange in the three ecosystems were calculated from the $\mathrm{CO}_{2}$ and $\mathrm{H}_{2} \mathrm{O}$ flux rates obtained with the portable infrared method described above:

Daily carbon exchange $=\int_{0: 00}^{24: 00} F c^{*} 12^{*} 10^{-6}(\mathrm{gC})$

Daily water exchange $=\int_{0: 00}^{24: 00} F h^{*} 18^{*} 10^{-6}\left(\mathrm{~kg} \mathrm{H}_{2} \mathrm{O}\right)$

where $F_{h}$ is the $\mathrm{H}_{2} \mathrm{O}$ flux (mmolm ${ }^{-2} \mathrm{~S}^{-1}$; positive $F_{h}$ values represent ecosystem vapor release; negative $F_{h}$ values represent vapor condensation). $F_{c}$ is the $\mathrm{CO}_{2}$ flux $\left(\mu \mathrm{molm}^{-2} \mathrm{~S}^{-1}\right.$; for NEE and GEP, positive $F_{c}$ represent ecosystem carbon uptake; for Re positive $F_{c}$ represents ecosystem carbon release).

\section{Canopy and ecosystem WUE}

The calculation of canopy water use efficiency (WUEc), defined as the ratio of GEP to T (Yepez et al. 2007), and ecosystem water use efficiency (WUEgep or WUEnep, the ratio of GEP to ET or the ratio of NEP to ET) (Beer et al. 2009; Niu et al. 2011) was calculated varied in instantaneous and daily scale.

Instantaneous canopy WUE was calculated as GEP/T (WUEc) according to the method of Niu (Niu et al. 2011).

Canopy $\mathrm{WUE}_{\mathrm{c}}=\mathrm{GEP} / \mathrm{T}$

Similar to canopy WUE, instantaneous ecosystem WUE was calculated with flux data as GEP/ET (WUEgep) or NEE/ET (WUEnee).

Ecosystem $\mathrm{WUE}_{\text {gep }}=\mathrm{GEP} / \mathrm{ET}, \mathrm{WUE}_{\text {nee }}=\mathrm{NEE} / \mathrm{ET}$

Daily WUE in different scales were calculated from the daily carbon/vapor accumulations obtained from daily flux rates:

Canopy $\mathrm{WUE}_{\mathrm{c}}=\mathrm{GEP} / \mathrm{T}$

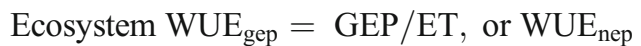

$$
=\mathrm{NEP} / \mathrm{ET}
$$

\section{Data analysis}

One-way ANOVA with Tukey's HSD test was used to analyze the differences of ecosystem microclimates and community and soil characteristics of the three land uses. The paired $t$ test was used to compare the diurnal dynamics of ecosystem vapor and carbon exchange as well as canopy and ecosystem WUE of the land uses. One-way ANOVA with Tukey's HSD test analyzed the mean daily accumulated ET, E, T, NEP, GEP, and $\mathrm{Re}$, and also the canopy and ecosystem WUE of the land uses. Linear regression analysis examined the consistency of NEE and ET measured by the eddy covariance system and portable infrared chamber method. Linear regression analysis was used to evaluate the relationships between LAI and ecosystem microclimate factors and WUE and its water and carbon exchange components. All statistical analyses were performed using SPSS 12.0.

\section{Results}

\section{Community and microclimate characteristics of land uses}

GE and $C$ had significantly more total biomass than $G$ and the components of biomass composition of the treatments differed 
Table 1 Community characteristics of the three land uses

\begin{tabular}{llll}
\hline Land use & Grazing $(G)$ & Grazing exclusion $(\mathrm{GE})$ & Crop $(C)$ \\
\hline Dominant species & Stipa grandis & Stipa grandis & Triticum aestivum \\
Cover (\%) & $56.3 \pm 2.4 \mathrm{a}$ & $95.0 \pm 2.0 \mathrm{~b}$ & $93.8 \pm 1.25 \mathrm{~b}$ \\
Height $(\mathrm{cm})$ & $14.75 \pm 0.95 \mathrm{a}$ & $56.25 \pm 5.54 \mathrm{~b}$ & $89.0 \pm 1.29 \mathrm{c}$ \\
Leaf area index LAI & $0.42 \pm 0.03 \mathrm{a}$ & $0.68 \pm 0.05 \mathrm{a}$ & $1.33 \pm 0.13 \mathrm{~b}$ \\
Total biomass $\left(\mathrm{kg} \mathrm{s}^{-1}\right)$ & $2.04 \pm 0.14 \mathrm{a}$ & $3.01 \pm 1.38 \mathrm{~b}$ & $1.02 \pm 0.06 \mathrm{c}$ \\
Aboveground/total biomass $(\%)$ & $3.73 \pm 0.20 \mathrm{a}$ & $5.95 \pm 0.29 \mathrm{~b}$ & $64.50 \pm 2.24 \mathrm{c}$ \\
$C_{4} /$ total biomass $(\%)$ & $32.98 \pm 1.70 \mathrm{a}$ & $6.10 \pm 2.26 \mathrm{~b}$ & 0 \\
Litter biomass $\left(\mathrm{g} / \mathrm{m}^{2}\right)$ & $1.60 \pm 0.55 \mathrm{a}$ & $84.81 \pm 4.47 \mathrm{~b}$ & $10.98 \pm 1.00 \mathrm{c}$ \\
\hline
\end{tabular}

Mean \pm SE. Different letters in the same line mean significant difference at $P<0.05$ significantly (Table 1). The LAI of cultivated ecosystem was the highest among the three land uses and also was the only land use that showed mean LAI higher than 1 . The mean LAI of grazing steppe was 0.42 , and the low SE (0.03) of its mean LAI suggests high homogeneity of $\mathrm{G}$. The LAI of $\mathrm{C}$ was three times higher than that of $\mathrm{G}(P<0.05)$. Mean LAI of grazing exclusion steppe was medium among the tree land uses, significantly lower than $\mathrm{C}$, but not significantly higher than $\mathrm{G}$. The LAI of GE was $81 \%$ lower than $\mathrm{C}(P<0.05)$.

Soil temperature of $\mathrm{G}$ was significantly higher than that of GE. Grazed steppe had the lowest soil moisture, $2.5 \%$ less than GE and $4.42 \%$ less than $\mathrm{C}$ (Table 2). Land use also significantly affected soil condition but had little effect on aerial microclimate factors including temperature and VPD. Clipping did not cause marked microclimate change for $\mathrm{G}$, but for $\mathrm{GE}$ and $\mathrm{C}$, there were significant differences between CL plots and CK plots for soil moisture and temperature (Table 2), whereas there were no significant differences of microclimate factors between paired DS and CK plots.

\section{Components of ET and WUE in response to different land uses}

The results of the two determination methods for ET and NEE for $\mathrm{G}$ were strongly correlated (Fig. 4). The diurnal dynamics of E (Fig. 5a), T (Fig. 5b), and ET (Fig. 5c) were similar and predominantly single-peak curves for the three land uses, and midday depressions were observed in ET and T. NEE of different land uses was similar in the day time, while cultivated land presented an enhanced carbon release at night (Fig. 5d). Re peaked after midday (12:00-15:00), and Re in cultivated area was significantly enhanced compared with the other two land uses (Fig. 5e). GEP presented midday rest in all the three land uses (12:00-15:00), and the highest GEP was appeared at 11:00 in cultivated land (Fig. 5f).

Compared with grazed steppe, cropping increased ET by $13.4 \%(P<0.05)$, whereas the increase for grazing excluded steppe was not significant $(P>0.05$, Fig. 6a, b). No significant differences were shown in mean daily $\mathrm{T}$ or the diurnal pattern among the three land use patterns (Fig. 6a). E of grazing
Table 2 Microclimate characteristics of land use types (LT) and vegetation cover treatments (TR)

\begin{tabular}{lllll}
\hline $\mathrm{LT} / \mathrm{Tr}$ & Soil temperature $\left({ }^{\circ} \mathrm{C}\right)$ & Soil moisture $(\%)$ & Air temperature $\left({ }^{\circ} \mathrm{C}\right)$ & Vapor pressure deficit $(\mathrm{kPa})$ \\
\hline $\mathrm{G}$ & & & & \\
$\mathrm{DS}$ & $20.68 \pm 0.81 \mathrm{a}$ & $21.98 \pm 0.81 \mathrm{a}$ & $21.84 \pm 1.00 \mathrm{a}$ & $1.72 \pm 0.14 \mathrm{a}$ \\
$\mathrm{CL}$ & $20.94 \pm 0.37 \mathrm{a}$ & $21.34 \pm 0.78 \mathrm{a}$ & $21.89 \pm 1.02 \mathrm{a}$ & $1.78 \pm 0.16 \mathrm{a}$ \\
$\mathrm{CK}$ & $19.82 \pm 0.71 \mathrm{ab}$ & $21.91 \pm 0.79 \mathrm{a}$ & $21.79 \pm 1.02 \mathrm{a}$ & $1.68 \pm 0.13 \mathrm{a}$ \\
$\mathrm{GE}$ & & & & \\
$\mathrm{DS}$ & $17.69 \pm 0.55 \mathrm{bc}$ & $26.10 \pm 0.56 \mathrm{bc}$ & $21.71 \pm 1.05 \mathrm{a}$ & $1.76 \pm 0.16 \mathrm{a}$ \\
$\mathrm{CL}$ & $18.47 \pm 0.32 \mathrm{~b}$ & $22.83 \pm 0.67 \mathrm{ab}$ & $22.01 \pm 1.08 \mathrm{a}$ & $1.81 \pm 0.16 \mathrm{a}$ \\
$\mathrm{CK}$ & $17.25 \pm 0.46 \mathrm{c}$ & $24.41 \pm 0.30 \mathrm{~b}$ & $21.63 \pm 0.97 \mathrm{a}$ & $1.68 \pm 0.14 \mathrm{a}$ \\
$\mathrm{C}$ & & & & \\
$\mathrm{DS}$ & $18.76 \pm 0.26 \mathrm{abc}$ & $27.09 \pm 0.51 \mathrm{c}$ & $23.15 \pm 0.89 \mathrm{a}$ & $1.29 \pm 0.14 \mathrm{a}$ \\
$\mathrm{CL}$ & $20.55 \pm 0.37 \mathrm{a}$ & $24.23 \pm 0.44 \mathrm{~b}$ & $23.39 \pm 0.90 \mathrm{a}$ & $1.28 \pm 0.14 \mathrm{a}$ \\
$\mathrm{CK}$ & $18.17 \pm 0.42 \mathrm{bc}$ & $26.33 \pm 0.14 \mathrm{c}$ & $23.09 \pm 0.86 \mathrm{a}$ & $1.22 \pm 0.13 \mathrm{a}$ \\
\hline
\end{tabular}

Different letters in the same column indicate statistical differences at $P<0.05$

$C K$ control, $D S$ dry standing, $C l$ clipped 

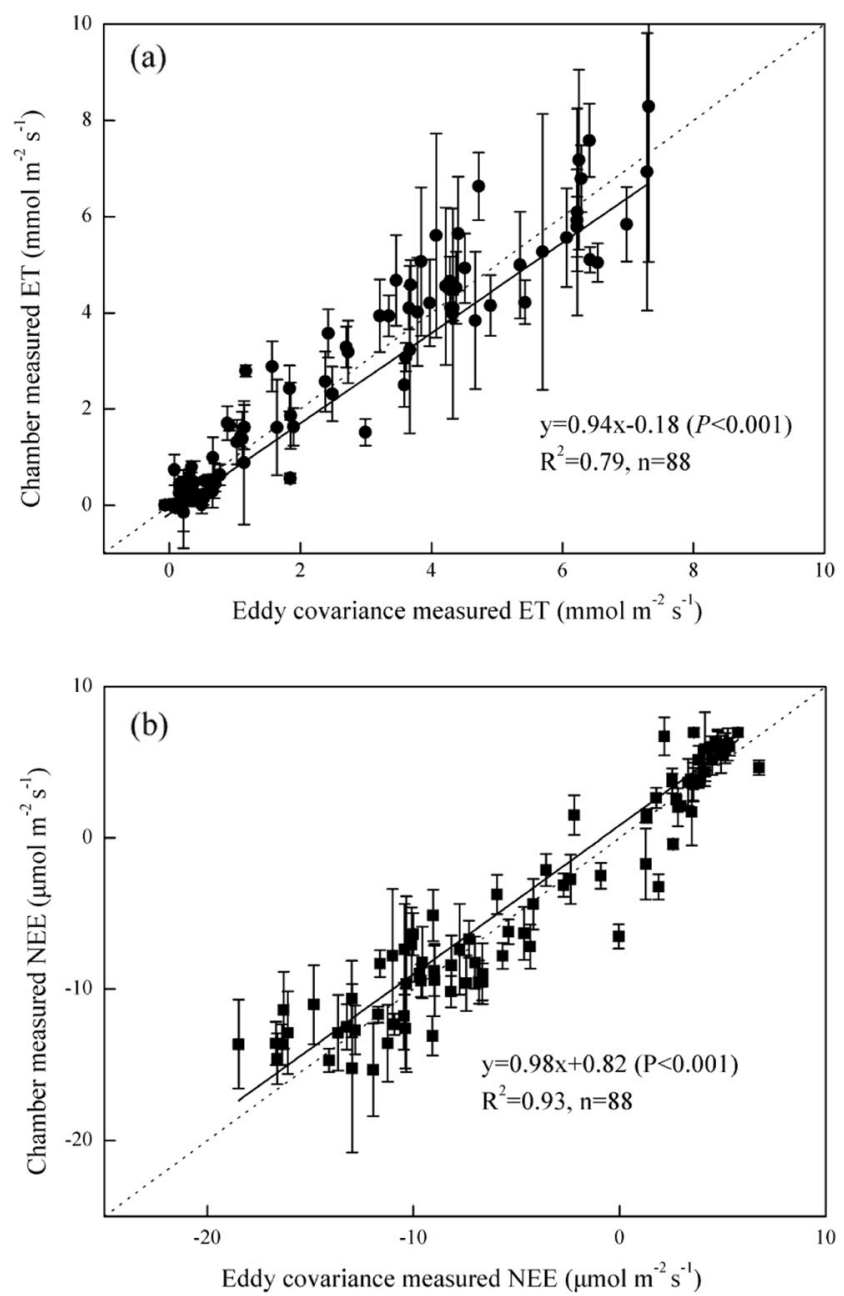

Fig. 4 Comparison of the ecosystem vapor (ET, a) and carbon exchange $(N E E, \mathbf{b})$ obtained by the chamber method and eddy covariance system. Eddy covariance data were obtained from the eddy covariance system located in the center of grazed grassland. Error bars are $1 \mathrm{SD}$ of mean chamber measured fluxes among blocks

excluded steppe was $24.3 \%$ more than grazed steppe $(P<0.05)$, and cropped steppe had $20.2 \%$ higher E than grazing excluded steppe (Fig. 6a). Consequently, the variation of ET among the land uses was due to differences of surface evaporation.

The effect of grassland use on WUEc was significant. For grazing exclusion (GE) and cultivation (C) canopy, WUEc were respectively 17 and $36 \%$ higher than WUEc of grazed steppe $(\mathrm{G})$, and $\mathrm{C}$ was $14 \%$ higher than $\mathrm{GE}(P<0.05$, Fig. $6 \mathrm{c})$. No significant differences of WUEgep were shown for the three land uses. WUEnep of cropland (C) was significantly lower than G by $34 \%$ and by $28 \%$ for GE (Fig. $6 \mathrm{c}$ ).

\section{LAI relationships with ecosystem and canopy WUE and related community characteristics}

Water use efficiency of canopy (WUEc) and ecosystem (WUEgep and WUEnep) scales were all significantly linearly correlated with community LAI (Fig. 7a-c), but the trends differed as WUEc and WUEgep were both positively related to LAI, whereas the trend for WUEnep was negative. In addition, the variation of community LAI was negatively correlated with soil temperature (Fig. 7d) and positively related to volumetric soil moisture (Fig. 7e), but not significantly related to air temperature (Fig. 7f). Moreover, LAI showed positive linear relationship with ecosystem ET (Fig. 7i) and surface E (Fig. $7 \mathrm{~g}$ ) but was not significantly related with canopy $\mathrm{T}$ (Fig. 7h). LAI had a positive linear relationship with GPP (Fig. 7 j) and Re (Fig. 71), and showed no significant relationship with NEE (Fig. 7k).

\section{Diurnal dynamics of canopy and ecosystem WUE and its driving factors}

The temporal dynamics of WUEc (Fig. 8a) and WUEgep (Fig. 8c) followed the diurnal patterns of E/ET (Fig. 8d) with all three land use values being lower at noon and higher in the morning and at sunset. WUEnee had a declining trend during the day, peaking in the morning from 7:00 to 8:00 a.m. for all three land uses (Fig. 8b).

Diurnal dynamics of canopy and ecosystem WUE exhibited significant relationships with their vapor consumption components ( $\mathrm{T}$ or ET), carbon exchange rate GEP, and microclimate factors including air temperature (AT) and net radiation (Rn) (Fig. 9). However, no significant trend was detected between NEE and WUEnee (Fig. 9c). Higher canopy and ecosystem WUE were obtained only when vapor consumptions (T or ET) were low, and this was shown in all calculated WUE scales (Fig. 9 a-c).

\section{Discussion}

To our knowledge, our study is the first to compare WUE responses to changed land use in northern China steppe. Clear understanding of these responses is crucial for the prediction of the potential impacts on regional vapor-carbon exchange and climate change related to the large-scale conversion of steppe to cultivated cropland that has occurred and is continuing in this sensitive ecotone (Wu et al. 2013).

\section{Difference of ET compositions among different land uses of steppe}

The ETs of grazed (3.29 $\mathrm{kg} \mathrm{m}^{-2}$ day $\left.^{-1}\right)$, grazing excluded $\left(3.52 \mathrm{~kg} \mathrm{~m}^{-2}\right.$ day $\left.^{-1}\right)$, and cultivated $\left(3.74 \mathrm{~kg} \mathrm{~m}^{-2}\right.$ day $\left.^{-1}\right)$ steppe observed in this study were comparable with those found by related research conducted on adjacent Inner Mongolia steppe (Chen et al. 2009b; Miao et al. 2009). Though there are few comparable results of divided ET components on similar steppe ecosystems (Lauenroth and 


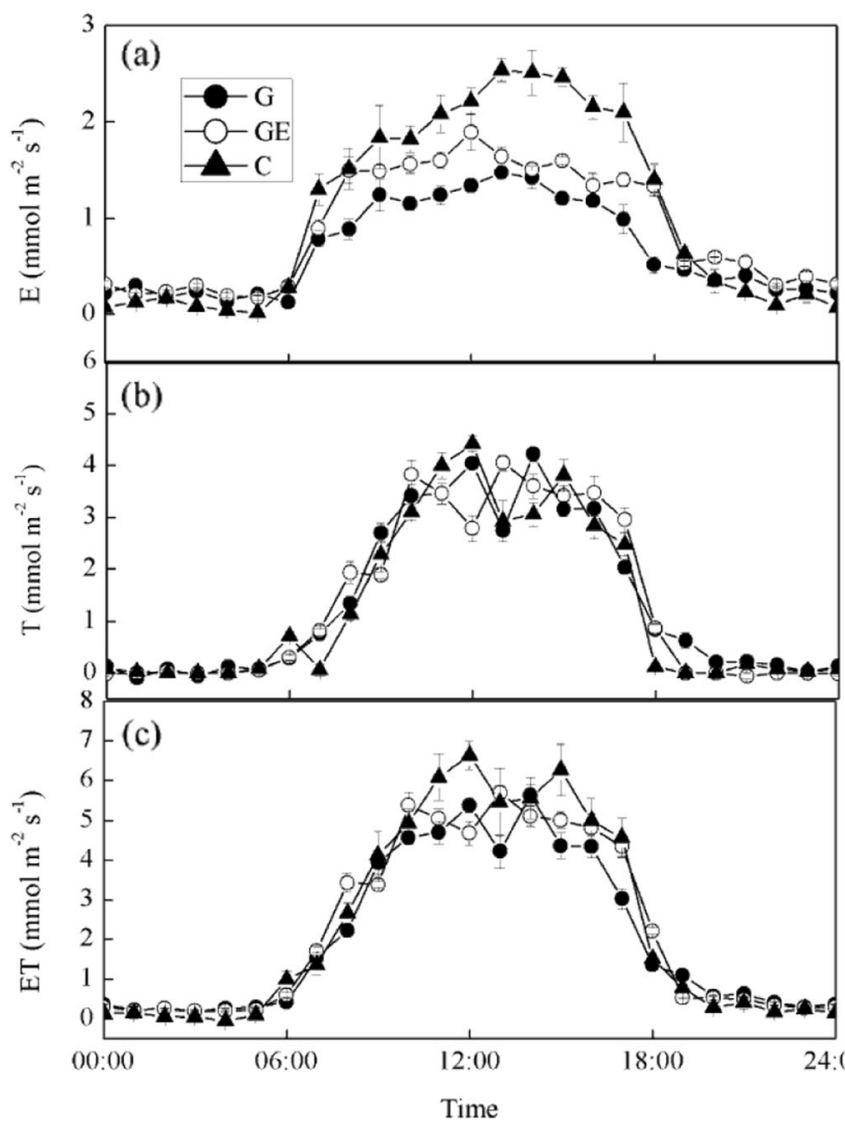

Fig. 5 Daily dynamics of vapor and carbon exchange compositions of different land uses during the peak growing period. Evaporation $(E, \mathbf{a})$, transpiration $(T, \mathbf{b})$, evapotranspiration $(E T, \mathbf{c})$, net ecosystem exchange

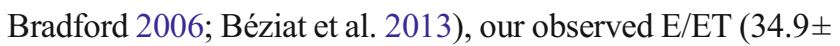
$0.7 \%$ ) results obtained in grazed steppe were similar to the modeled E/ET for a similar ecosystem (Hu et al. 2008). The observed components E, T (Fig. 5a, b), and E/ET (Fig. 6a) were larger than those determined in Duolun County to the south of our research site (Niu et al. 2011). These differences may not only be due to the temporal-spacial differences of these sites but also due to differences in the determination method of surface $\mathrm{E}$ as their clipping method would have considerably changed the environmental conditions closely related with E (Niu et al. 2008; Niu et al. 2009; Xu et al. 2013). Canopy removal makes the surface soil significantly drier (Table 2) especially for the higher cover land uses (GE and $\mathrm{C}$ ), and this results in underestimation of surface $\mathrm{E}$ (Knapp and Smith 2001; Huxman et al. 2004), although increased soil temperature (Table 2) would cause opposite effects (Luo et al. 2008).

ET and NEE rates determined by the eddy covariance system in our study were highly correlated with ET and NEE rates measured by using the chamber method (Fig. 4, $P<0.001$ ), which implied the reliability of chamber-measured vapor exchange rates. Nevertheless, applying the herbicide methods to divide vapor fluxes may still bring possible errors to the
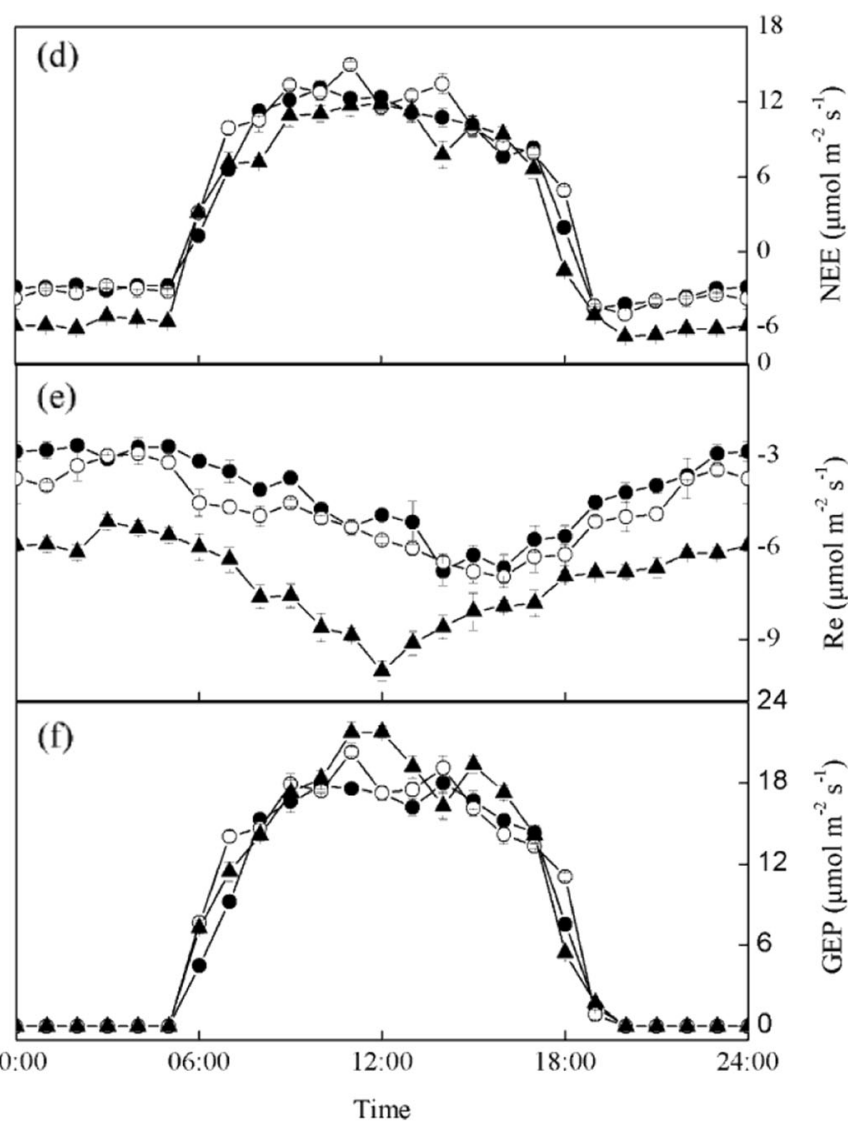

$(N E E, \mathbf{d})$, ecosystem respiration $(R e, \mathbf{e})$, and gross ecosystem productivity $(G E P$, f). Error bar=1 SE. $G$ grazing, $G E$ grazing excluded, $C$ crop

evaporation determination. One is that the physical traits of dried death biomass (e.g., albedo) are considerably different from living vegetation, which would change the original net radiation. Moreover, some important original meteorological factors (e.g., wind) were not completely represented in the chamber device ( $\mathrm{Li}$ et al. 2008), which may partly limit the accurate determination of ecosystem fluxes. Furthermore, though the peak growing season contribute the most of the annual ecosystem vapor/carbon exchange in steppe (Lauenroth et al. 2000; Miao et al. 2009), our short time period observation (12 days in total, observed only in the peak growing season) still limited the accurate assessment of the annual mass budget of different land uses of steppe ecosystem. However, the fluxes observation with the chamber method cost too much manpower and time. Thus, the automatic recording of eddy covariance system shows an irreplaceable advantage in long-term observation. Special models which combine the fluxes partition ability of chamber method with long-term observation of eddy covariance system would largely promote our understanding on ecosystem mass budget.

Consistent with previous results, our results convinced that cropping and grazing exclusion increased ecosystem ET in 

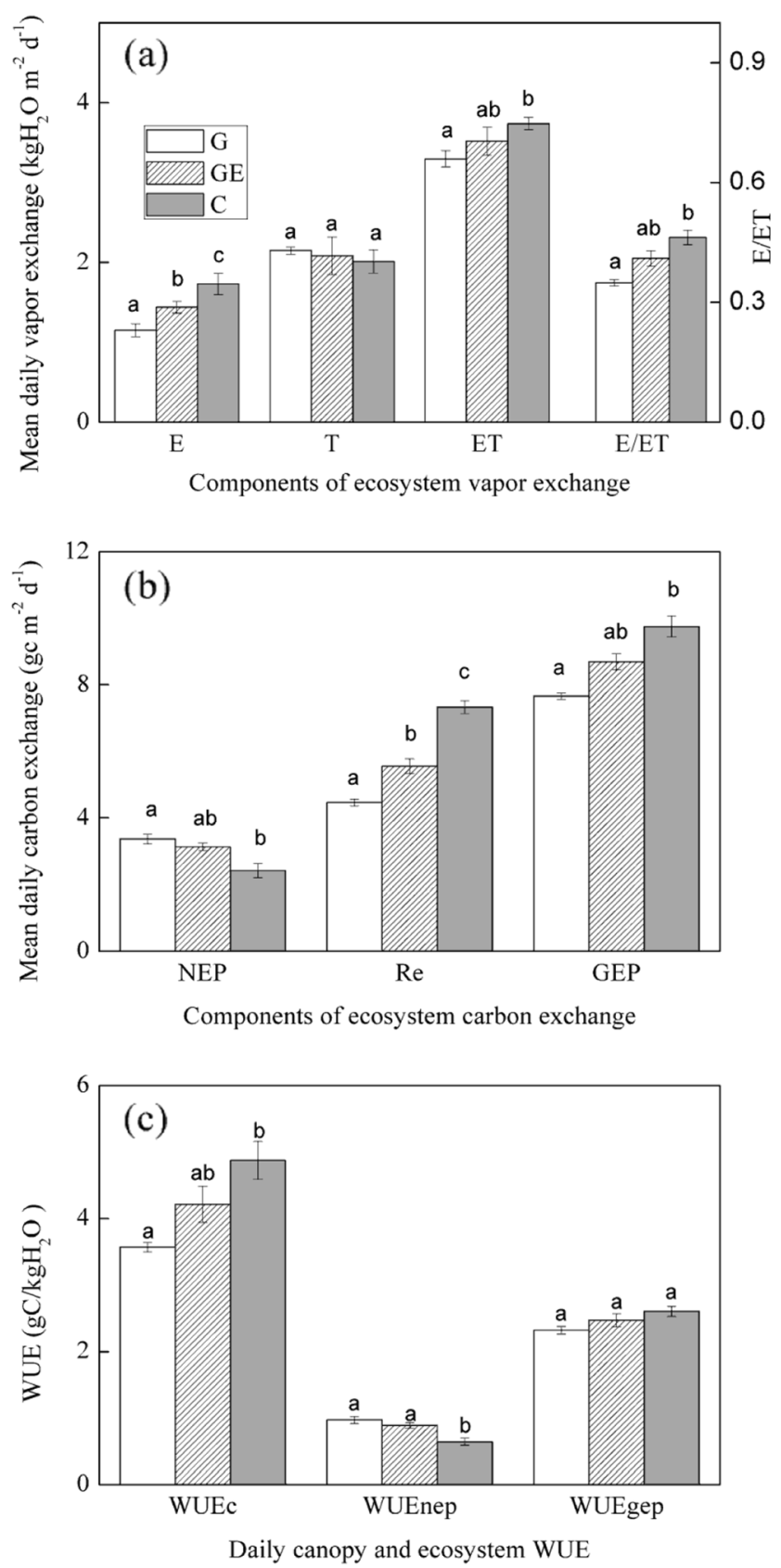

Fig. 6 Mean daily (a) ecosystem vapor consumption $(E, T, E T$, and $E / E T)$, (b) carbon budget (NEP, Re, and GEP), and (c) canopy (WUEc), ecosystem water-use efficiency (WUEnep and WUEgep) for different steppe grassland uses. The values represent the daily mean values (means $\pm 1 \mathrm{SE}$ ) in the peak growing period. Different letters in each bar group indicate significant difference $(P<0.05)$. $G$ grazing, $G E$ grazing excluded, $C$ crop

steppe area (Miao et al. 2009; Béziat et al. 2013). However, with our methods of cutting off or killing the canopy with herbicide, our results indicate that the variation of ET among the different land uses was mainly due to the change of E, whereas $T$ was not significantly affected by the grassland steppe use (Fig. 6a). This is different from some previous large-scale studies which have indicated that the positive relationship of canopy T with LAI varied for vegetation types (Hu et al. 2008) and for different periods of the growing season (Hu et al. 2008; Miao et al. 2009). Though LAI also increased in the grazing excluded and cropping land uses (Table 2), their significant increase of $\mathrm{E}$ in our results (Fig. 6a) is more likely explained by the increase of their volumetric soil moisture (both, $P<0.05$ ), as this change of soil characteristic directly enhanced the capacity of vapor consumption (Hu et al. 2009). Especially in adjacent temperate steppes, soil water supply is considered as the most important limiting factor for surface $\mathrm{E}$ and ecosystem ET (Miao et al. 2009; Niu et al. 2011).

Compared with grazed steppe, the higher LAI in cultivated and grazing excluded land use strengthen the interception of rain, which largely decreased the soil erosion by preventing direct raindrop. This change would gradually lower the soil bulk density (Table 1) and improve the soil porosity, which consequently promoted the evaporation of soil (Fig. 5a). Besides, the increase of LAI of cultivated steppe and grazing excluded steppe, and also the accumulation of litter in grazing excluded steppe, enhanced shading of the soil surface (Table 1), contributing to their increased soil volumetric moisture content (Table 2). These two cases may explain how $\mathrm{E}$ is stimulated by change of steppe land use. Additionally, the vapor consumption process (T or ET) would closely correlate with plant photosynthesis processes (e.g., GEP and NEE) (Chen et al. 2009b; Xu et al. 2013). Therefore, the influence of grassland use on the ET budget should be a key factor in determining WUE for both ecosystem and canopy scales (Brümmer et al. 2012).

\section{Difference of daily WUE among different land use patterns of steppe}

WUE has been intensively analyzed at the leaf scale through chamber and isotopic methods and at regional scales through modeling within remotely sensed data (Niu et al. 2011; Béziat et al. 2013; Kool et al. 2014). In this study, we examined ecosystem and canopy WUE and their variation under different uses of Stipa steppe land. This approach provides an improved estimate of steppe ecosystem WUE affected by the difference of land use, since the ecosystem water consumption was divided into the canopy transpiration $(\mathrm{T})$ and water loss from the soil surface $(\mathrm{E})$.

In our study, the overall mean daily WUEc observed in the three land uses (3.6-4.9 $\mathrm{g} \mathrm{C} \mathrm{kg}^{-1} \mathrm{H}_{2} \mathrm{O}$ ) is comparable with that of another Inner Mongolia steppe site $\left(2.1-4.6 \mathrm{~g} \mathrm{C} \mathrm{kg}^{-1}\right.$ $\mathrm{H}_{2} \mathrm{O}$ ) (Niu et al. 2011). Compared with grazed steppe, the grazing excluded and cropped steppe showed higher WUEc (Fig. 7a) during the peak growing period. This variation may be contributed by the change of LAI, as increased LAI significantly stimulated GEP (Figs. 6b and 7j), whereas canopy transpiration $(\mathrm{T})$ was not significantly influenced by change 

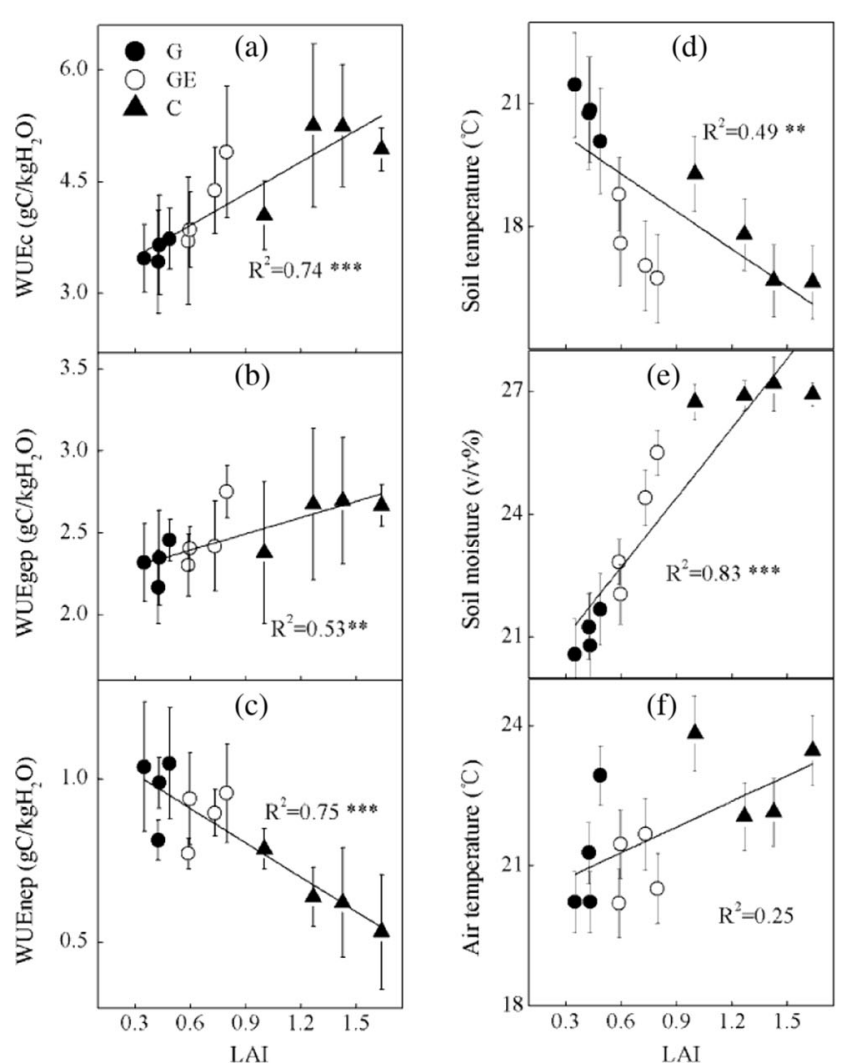

Fig. 7 Relationships between LAI and mean daily water use efficiency indices (WUEc, a; WUEnep, b; WUEgep, c), ecosystem micrometeorological factors $(S T, \mathbf{d} ; S M, \mathbf{e} ; A T, \mathbf{f})$, water exchange $(E, \mathbf{g}$; $T, \mathbf{h} ; E T, \mathbf{I})$, and carbon exchange $(N E P, \mathbf{j} ; \operatorname{Re}, \mathbf{k} ; G E P, \mathbf{l})$ across the three
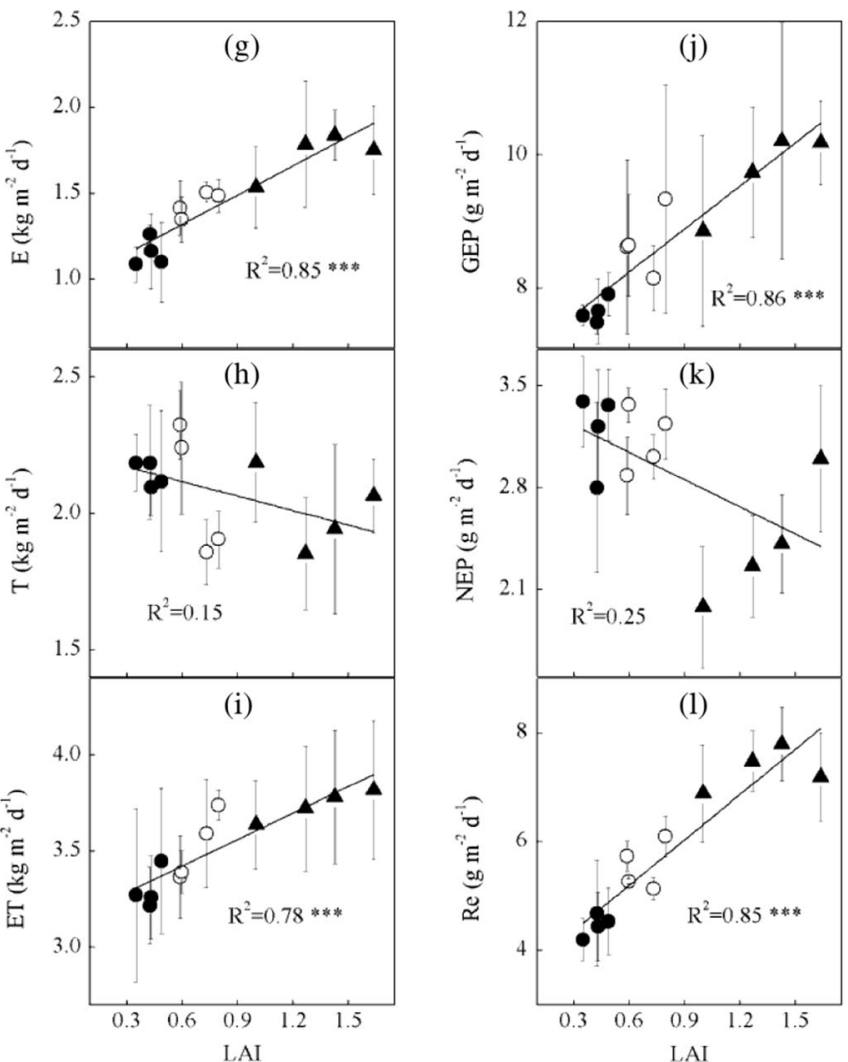

land uses. Error bars are $1 \mathrm{SE}$ of 4-day replicates in each block. $R^{2}$ and probabilities of regressions are shown. ${ }^{*} P<0.05 ; * * P<0.01$; $* * * P<0.001$. $S T$ soil temperature, $S M$ soil moisture, $A T$ air temperature, $G$ grazing, $G E$ grazing excluded, $C$ crop
Fig. 8 Diurnal patterns of canopy ( WUEc, a), ecosystem water-use efficiency (WUEnee, $\mathbf{b}$ and WUEgep, c) and ecosystem ET composition $(E / E T, \mathbf{d})$ for the three land uses during the peak growing period. $G$ grazing, $G E$ grazing excluded, $C$ crop

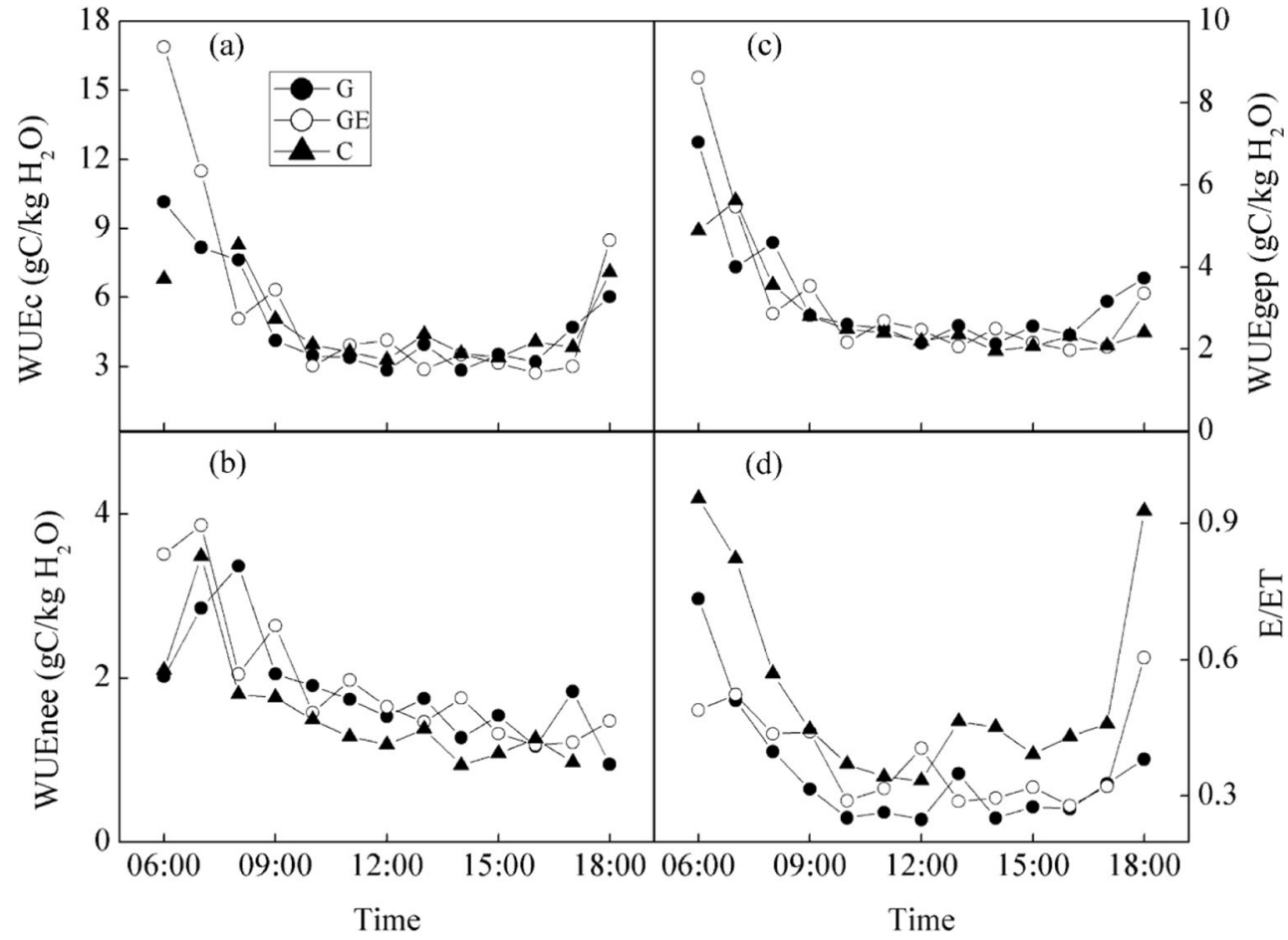



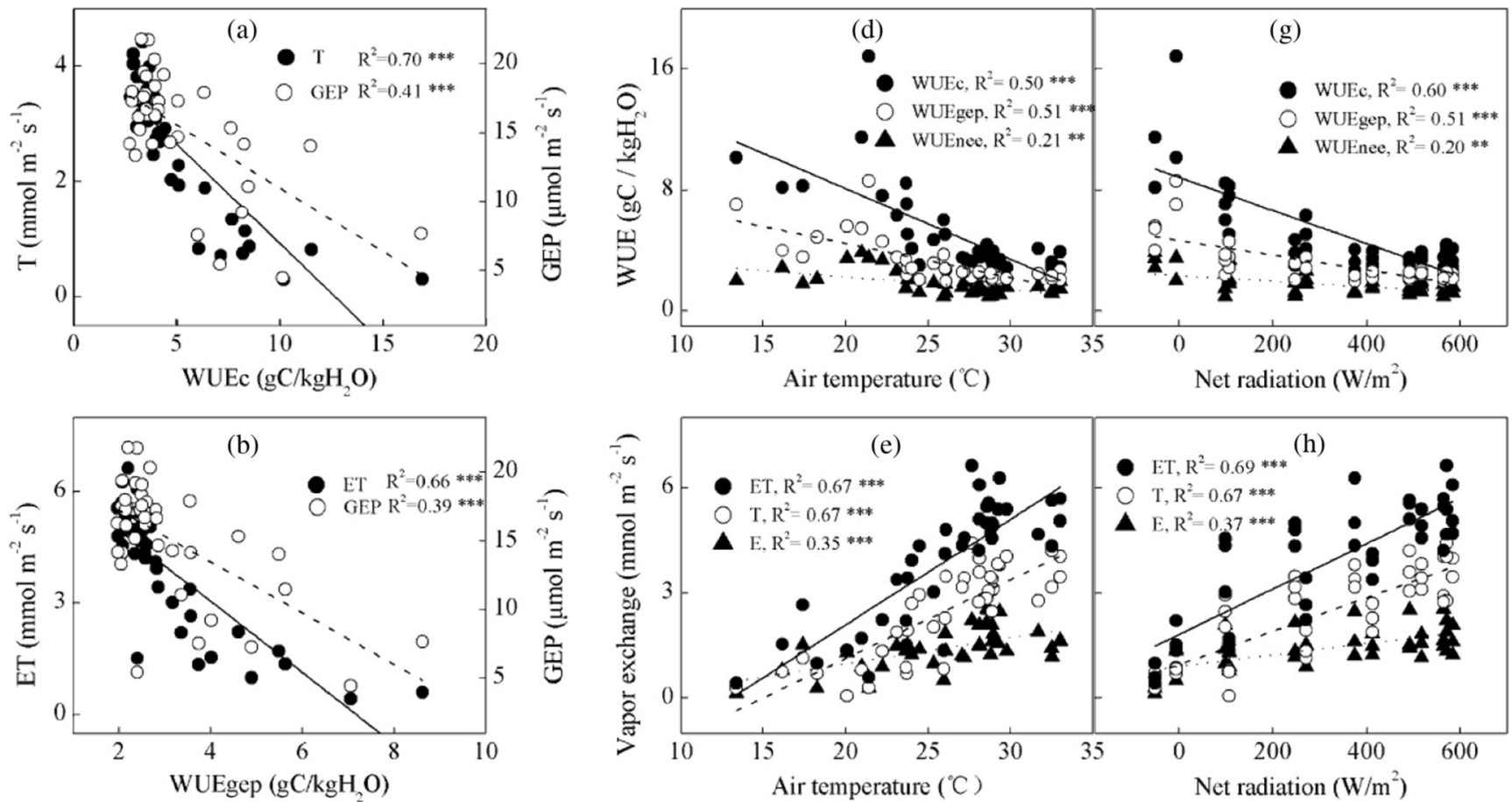

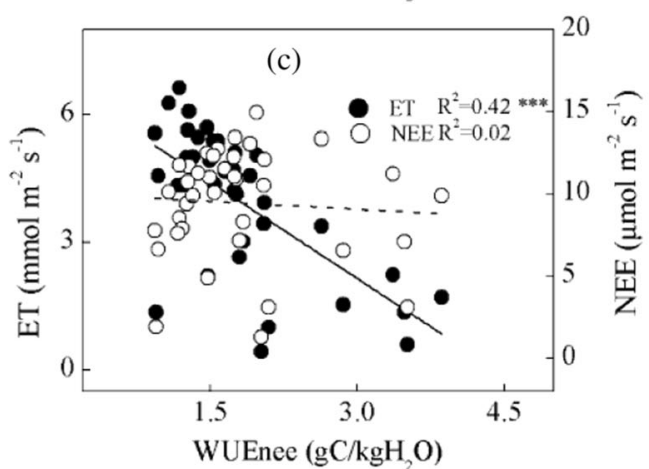

Fig. 9 Relationships between diurnal canopy $(W U E c$, a) or ecosystem water-use efficiency (WUEgep, $\mathbf{b}$, and WUEnee, c) on vapor carbon exchanges, and WUE $(\mathbf{d}, \mathbf{g})$, vapor $(\mathbf{e}, \mathbf{h})$, and carbon $(\mathbf{f}, \mathbf{i})$ exchanges

of LAI (Figs. 6a and 7h). The insignificant trends between LAI and T were mainly due to the similar transpiration losses among different land uses. In large-scale and long-term studies, LAI was indicated positively correlated with $\mathrm{T}$ (Brümmer et al. 2012; Hu et al. 2008), while transpiration was not significantly different among adjacent maize and wheat croplands with varied LAI (Béziat et al. 2013). Results of Béziat's study supported the conclusion that the impacts of LAI variation on $\mathrm{T}$ among adjacent land uses were largely different from regulations across vegetation types and growing periods. The similar transpiration among adjacent land uses (Fig. 6a) may be attributed to several possible reasons. Primarily, micrometeorological factors (e.g., air temperature and VPD, Table 2) which verified closely regulating the transpiration were not significantly changed among different land uses. Additionally, the hydropenic condition may compel the vegetation of different land uses with varied LAI to reduce their transpiration losses to a limit level by biophysical way (e.g., changing the leaf angle, curling the leaves, or regulating the stoma conductance) (Raeini-Sarjaz and Chalavi 2008); these adapting strategy would largely help the species surviving in this semiarid temperate steppe. At last, the insignificant correlations may attribute to our relative small sample size, which will also limit the generalization of our results. Our observed WUEgep (2.3-2.6 g C kg $\mathrm{g} \mathrm{H}_{2} \mathrm{O}$ ) is within the limits of results modeled from eddy covariance data $(1.1-5.1 \mathrm{~g}$ $\mathrm{C} \mathrm{kg}^{-1} \mathrm{H}_{2} \mathrm{O}$ ) (Hu et al. 2008). Though the water loss data was replaced from $\mathrm{T}$ to $\mathrm{ET}$, the dynamic of WUEgep was still very similar to WUEc (Figs. 6c and 7b). This situation was reported in previous studies (Beer et al. 2009; Niu et al. 2011). Opposite to WUEc and WUEgep, WUEnep in cropland (around $0.9 \mathrm{~g} \mathrm{C} \mathrm{kg}^{-1} \mathrm{H}_{2} \mathrm{O}$ ) was significantly lower than that in grazed and grazing excluded steppe (Fig. 6c). This may be partly attributed to the inherently high Re (Fig. 5e) of 
agricultural species (Table 1). The significantly lower NEP and WUEnep of cropland (Fig. 6c) indicated that large-scale cultivation and conversion to cropland could weaken the carbon sequestration function of northern China steppe (Fan et al. 2008). Additionally, the water consumption (E and ET) by cropland is markedly increased (Fig. 6a), and if continued for long terms would result in groundwater loss, causing serious consequences for this arid and semiarid region.

According to long-term observations, rising levels of atmospheric $\mathrm{CO}_{2}$ could stimulate WUEnep (Enoch and Hurd 1979; Keenan et al. 2013). Some manipulative experiments have found ecosystem WUE to be closely related to water consumption factors, including T/ET (Hu et al. 2008), annual precipitation (Niu et al. 2011), and soil moisture (Kool et al. 2014). Moreover, LAI has been indicated as a key driving factor of ecosystem WUE in several observational and modeling studies (Hu et al. 2008; Beer et al. 2009; Kool et al. 2014). Similar to the conclusions of these studies, close correlations between ecosystem WUE (Fig. 7b, c), canopy WUE (Fig. 7a), and LAI were observed.

In our study, LAI explained $74 \%$ of the changes of WUEc (Fig. 7a) and $75 \%$ of WUEnep (Fig. 7c). Furthermore, changes of LAI among the different land uses are highly relevant to changes of GEP (Fig. 7j) and Re (Fig. 71), which is consistent with previous studies (Xiao et al. 2004; Xiao et al. 2005). Additionally, our results suggest that the water supply factor controlling of WUE was inherently related to LAI change and significant positive relations were observed between E, ET, and LAI (Fig. 7g, i). This might be attributed to the close regulation between LAI and microclimate.

By enhancing canopy shading (Table 1), increased LAI largely heightened the soil moisture (Fig. 7e). Soil moisture was verified as a key factor regulating ecosystem carbonwater exchange (Kurbatova et al. 2008; Luo et al. 2008) and especially played an important role in controlling evaporation in temperate steppe area (Niu et al. 2008; Niu et al. 2009). A previous study (Hu et al. 2008) concluded that water supply was an important factor controlling that WUE is consistent with our findings. Changes of LAI among the different land uses are highly relevant to changes of their microclimates and ecosystem $\mathrm{C}$-water exchange processes. As a consequence, LAI variation played a key role in controlling ecosystem and canopy WUE in the different land uses.

\section{Diurnal dynamics of canopy and ecosystem WUE and its relationship with microclimatic factors}

At the temporal scale, WUE has been studied through growing seasons and inter-annually (Hu et al. 2008; Niu et al. 2008; Niu et al. 2011). These longer term studies have contributed to the construction of ecological models that roughly simulate water-carbon budgets for various climatic scenarios (Niu et al. 2011). However, there have been few studies on the response of diurnal ecosystem or canopy WUE to environmental factors (Hu et al. 2010). It is the consensus that control of WUE varies with the scale of analysis (Niu et al. 2011). Thus, limited understanding of the diurnal dynamics of ecosystem WUE adds to the difficulty of accurately modeling water-carbon budgets.

With reference to WUE diurnal dynamics studied at the leaf level (Zur and Jones 1984; Wraith et al. 1987; Dang et al. 1991), our results showed that the diurnal dynamics of WUEc and WUEgep were similar to leaf scale WUE at the species level. Similar to WUEc (Fig. 8a) and WUEgep (Fig. 8c) in our study, most species leaf scale WUE were lower at mid-day.

Previous studies at the leaf scale reported that the diurnal dynamic controlling factors of WUE include leaf transpiration, stomatal conductance, and VPD, which were also relevant to the vapor release process (Zur and Jones 1984; Mu et al. 2005; Raeini-Sarjaz and Chalavi 2008; Keenan et al. 2013). This may reflect that leaf photosynthesis (GPP and NEE) is primarily related to transpiration rate at the leaf scale, because of the shared passage of vapor and $\mathrm{CO}_{2}$ through leaf stomata, similar correlations were observed in study using long-term eddy covariance data (Hu et al. 2008). Our results confirm that the diurnal dynamics of canopy (Fig. 9a) and ecosystem (Fig. 9b, c) WUE were both closely related to the rate of canopy transpiration, ecosystem evapotranspiration, and GEP. Further, the T and ET consistently explain the changes of WUEc (Fig. 9a) or WUEgep (Fig. 9b) better than GEP rate by 29 and $27 \%$, respectively. This may indicate that the diurnal dynamics of canopy and ecosystem WUE are primarily controlled by vapor consumption rather than by the carbon uptake process in arid and semiarid regions.

Although there are a few long-term observational studies of grassland WUE that suggest that carbon uptake is more relevant to WUE variation than water consumption (Niu et al. 2011), it is important to note that WUE may show diverse responses for different temporal scales or organism levels (Tu et al. 2008). A possible reason for the strong negative response of canopy and ecosystem WUE to ecosystem vapor release rate (E or ET) is that leaf stomata are regulated by $\mathrm{Rn}$ and AT changes. All the forms of ecosystem carbon uptake (GEP and NEE) and vapor consumption (E, T, and ET) are positively related with Rn and AT for the diurnal scale (Fig. 9). The negative correlations of WUE with Rn (Fig. 8g) and AT (Fig. 9d) indicate that the increases of carbon uptake did not offset the increase in water consumption since Rn and AT increased at midday. Indeed, transpiration rate at midday was 70 times higher than that in the morning, while the GEP was just five times higher. This demonstrates that stomata expand at midday allowing greater loss of $\mathrm{H}_{2} \mathrm{O}$ resulting in evident ineffective water losses as Rn and AT increased. Our results provide direct observational evidence that ecohydrological processes are the primary drivers of the 
diurnal dynamics of canopy and ecosystem WUE. These findings will facilitate improvement of process-based terrestrial ecosystem models and our understanding of WUE response to changes of Stipa steppe use.

\section{Conclusion}

We used the chamber method to separate specific components of NEE and ET in three uses of Stipa steppe-land and evaluated how canopy and ecosystem WUE and their components responded to the community characteristics and microclimate difference of the land uses. We found that grazing exclusion and cultivation for crop production significantly increased ecosystem E, but $\mathrm{T}$ did not change significantly. Raised water consumption (E and ET) resulted in the decrease of WUEnep, whereas WUEc and WUEgep showed opposite trends. Mean daily canopy and ecosystem WUE responses to different steppe uses were primarily controlled by changes of LAI. The negative correlation between WUEnep and LAI suggests that large-scale grassland restoration and cultivation for cropping, by substantially raising LAI, could potentially reduce the carbon sequestration ability and concurrently increase vapor release of the arid and semiarid ecosystems of northern China. These negative impacts have to be balanced against the contribution of these land uses to food production and the provision of cover to reduce wind erosion that causes dust storms that impact on densely populated areas to the south of the steppe lands. The canopy and ecosystem WUE diurnal dynamic were predominantly driven by the change of vapor release rate (E and ET). Lower WUE at midday suggested that water loss was enhanced by stoma expansion in response to raised levels of Rn and AT.

Our results provide direct field evidence that land use changes of Stipa steppe actually influence the different ecohydrological components and modify the carbon-water budget of steppe, thus markedly changing the WUE and ecosystem function of the steppe. These findings will facilitate the improvement and validation of process-based terrestrial ecosystem models and increase our understanding of the response of northern China steppe to ongoing large-scale land use changes.

\footnotetext{
Acknowledgments We thank Prof. Jiyuan Liu for their helpful comments on an earlier version of this manuscript and Yao Bo, Zhang Liangxia, and Yu Hailing for their help in laboratory measurements. This research was jointly funded by the State Key Technologies R\&D Program (grant no. 2013BAC03B04), Natural Sciences Foundation of China (41371409 and 41301043), Youth Innovation Promotion Association, CAS (2015037), and the Funding for talented young scientists of IGSNRR (2013RC203). In addition, the authors thank Dr. Qi Wei for his help in improving their figures, as well as the editor and two anonymous reviewers for their constructive comments, which helped them to improve the paper.
}

\section{References}

Béziat P, Rivalland V, Tallec T, Jarosz N, Boulet G, Gentine P, Ceschia E (2013) Evaluation of a simple approach for crop evapotranspiration partitioning and analysis of the water budget distribution for several crop species. Agric For Meteorol 177:46-56

Bai W, Wan S, Niu S, Liu W, Chen Q, Wang Q, Zhang W, Han X, Li L (2010) Increased temperature and precipitation interact to affect root production, mortality, and turnover in a temperate steppe: implications for ecosystem C cycling. Glob Chang Biol 16(4):1306-1316

Bai Y, Wu J, Xing Q, Pan Q, Huang J, Yang D, Han X (2008) Primary production and rain use efficiency across a precipitation gradient on the Mongolia plateau. Ecology 89(8):2140-2153

Beer C, Ciais P, Reichstein M, Baldocchi D, Law B, Papale D, Soussana JF, Ammann C, Buchmann N, Frank D (2009) Temporal and among-site variability of inherent water use efficiency at the ecosystem level. Global biogeochemical cycles 23:2

Brümmer C, Black TA, Jassal RS, Grant NJ, Spittlehouse DL, Chen B, Nesic Z, Amiro BD, Arain MA, Barr AG (2012) How climate and vegetation type influence evapotranspiration and water use efficiency in Canadian forest, peatland and grassland ecosystems. Agric For Meteorol 153:14-30

Bremer DJ, Auen LM, Ham JM, Owensby CE (2001) Evapotranspiration in a Prairie Ecosystem. Agronomy Journal 93(2):338-348

Chen S, Chen J, Lin G, Zhang W, Miao H, Wei L, Huang J, Han X (2009a) Energy balance and partition in Inner Mongolia steppe ecosystems with different land use types. Agric For Meteorol 149(11): 1800-1809

Chen S, Lin G, Huang J, Jenerette GD (2009b) Dependence of carbon sequestration on the differential responses of ecosystem photosynthesis and respiration to rain pulses in a semiarid steppe. Glob Chang Biol 15(10):2450-2461

Dang Q, Lieffers V, Rothwell R, Macdonald S (1991) Diurnal variation and interrelations of ecophysiological parameters in three peatland woody species under different weather and soil moisture conditions. Oecologia 88(3):317-324

Enoch H, Hurd R (1979) The effect of elevated CO2 concentrations in the atmosphere on plant transpiration and water use efficiency. A study with potted carnation plants. Int J Biometeorol 23(4):343-351

Fan J, Zhong H, Harris W, Yu G, Wang S, Hu Z, Yue Y (2008) Carbon storage in the grasslands of China based on field measurements of above-and below-ground biomass. Climatic Change 86(3):375-396

Fisher JB, Tu KP, Baldocchi DD (2008) Global estimates of the landatmosphere water flux based on monthly AVHRR and ISLSCP-II data, validated at 16 FLUXNET sites. Remote Sensing of Environment 112(3):901-919

Hall DO, Scurlock J (1991) Climate change and productivity of natural grasslands. Annals of Botany 67(supp1):49-55

Hu Z, Yu G, Fan J, Zhong H, Wang S, Li S (2010) Precipitation-use efficiency along a 4500-km grassland transect. Global Ecology and Biogeography 19(6):842-851

Hu Z, Yu G, Fu Y, Sun X, Li Y, Shi P, Wang Y, Zheng Z (2008) Effects of vegetation control on ecosystem water use efficiency within and among four grassland ecosystems in China. Glob Chang Biol 14(7):1609-1619

Hu Z, Yu G, Zhou Y, Sun X, Li Y, Shi P, Wang Y, Song X, Zheng Z, Zhang L (2009) Partitioning of evapotranspiration and its controls in four grassland ecosystems: application of a two-source model. Agric For Meteorol 149(9):1410-1420

Huxman TE, Smith MD, Fay PA, Knapp AK, Shaw MR, Loik ME, Smith SD, Tissue DT, Zak JC, Weltzin JF (2004) Convergence across biomes to a common rain-use efficiency. Nature 429(6992):651-654

Keenan TF, Hollinger DY, Bohrer G, Dragoni D, Munger JW, Schmid $\mathrm{HP}$, Richardson AD (2013) Increase in forest water-use efficiency as 
atmospheric carbon dioxide concentrations rise. Nature 499(7458): 324-327

Knapp AK, Smith MD (2001) Variation among biomes in temporal dynamics of aboveground primary production. Science 291(5503): 481-484

Kool D, Agam N, Lazarovitch N, Heitman J, Sauer T, Ben-Gal A (2014) A review of approaches for evapotranspiration partitioning. Agric For Meteorol 184:56-70

Kurbatova J, Li C, Varlagin A, Xiao X, Vygodskaya N (2008) Modeling carbon dynamics in two adjacent spruce forests with different soil conditions in Russia. Biogeosciences 5(4):969-980

Lauenroth W, Bradford J (2006) Ecohydrology and the partitioning AET between transpiration and evaporation in a semiarid steppe. Ecosystems 9(5):756-767

Lauenroth WK, Burke IC, Paruelo JM (2000) Patterns of production and precipitation-use efficiency of winter wheat and native grasslands in the central Great Plains of the United States. Ecosystems 3(4):344-351

Li SG, Eugster W, Asanuma J, Kotani A, Davaa G, Oyunbaatar D, Sugita M (2008) Response of gross ecosystem productivity, light use efficiency, and water use efficiency of Mongolian steppe to seasonal variations in soil moisture. Journal of Geophysical Research: Biogeosciences (2005-2012) 113 (G1). doi:G0101910.1029/ 2006jg000349

Liu J, Liu M, Zhuang D, Zhang Z, Deng X (2003) Study on spatial pattern of land-use change in China during 1995-2000. Science in China Series D: Earth Sciences 46(4):373-384

Liu YY, van Dijk AI, de Jeu RA, Canadell JG, McCabe MF, Evans JP, Wang G (2015) Recent reversal in loss of global terrestrial biomass. Nature Climate Change 5:470-474

Luo Y, Gerten D, Le Maire G, Parton WJ, Weng E, Zhou X, Keough C, Beier C, Ciais P, Cramer W (2008) Modeled interactive effects of precipitation, temperature, and [CO2] on ecosystem carbon and water dynamics in different climatic zones. Glob Chang Biol 14(9): 1986-1999

Miao H, Chen S, Chen J, Zhang W, Zhang P, Wei L, Han X, Lin G (2009) Cultivation and grazing altered evapotranspiration and dynamics in Inner Mongolia steppes. Agric For Meteorol 149(11):1810-1819

Mu Z-X, Zhang S-Q, Hao W-F, Liang A-H, Liang Z-S (2005) The effect of root morphological traits and spatial distribution on WUE in maize. Acta Ecologica Sinica 25(11):2895-2900

Niu S, Sherry RA, Zhou X, Luo Y (2013) Ecosystem carbon fluxes in response to warming and clipping in a tallgrass prairie. Ecosystems 16(6):948-961
Niu S, Wu M, Han Y, Xia J, Li L, Wan S (2008) Water-mediated responses of ecosystem carbon fluxes to climatic change in a temperate steppe. New Phytologist 177(1):209-219

Niu S, Xing X, Zhang Z, Xia J, Zhou X, Song B, Li L, Wan S (2011) Water-use efficiency in response to climate change: from leaf to ecosystem in a temperate steppe. Glob Chang Biol 17(2):1073-1082

Niu S, Yang H, Zhang Z, Wu M, Lu Q, Li L, Han X, Wan S (2009) Nonadditive effects of water and nitrogen addition on ecosystem carbon exchange in a temperate steppe. Ecosystems 12(6):915-926

Raeini-Sarjaz M, Chalavi V (2008) Pulvinus activity, leaf movement and leaf water-use efficiency of bush bean (Phaseolus vulgaris L.) in a hot environment. Int J Biometeorol 52(8):815-822

Scurlock J, Hall D (1998) The global carbon sink: a grassland perspective. Glob Chang Biol 4(2):229-233

Tu K, Knohl A, Mambelli S, Ma S, Baldocchi D, Dawson T (2008) Observations and scaling of water use efficiency from leaf to globe. Geophysical Research Abstracts 10:07012

Wraith J, Johnson D, Hanks R, Sisson D (1987) Soil and plant water relations in a crested wheatgrass pasture: response to spring grazing by cattle. Oecologia 73(4):573-578

Wu F, Zhan J, Yan H, Shi C, Huang J (2013) Land cover mapping based on multisource spatial data mining approach for climate simulation: a case study in the farming-pastoral ecotone of North China. Advances in Meteorology 2013:12

Xiao X, Zhang Q, Braswell B, Urbanski S, Boles S, Wofsy S, Moore B III, Ojima D (2004) Modeling gross primary production of temperate deciduous broadleaf forest using satellite images and climate data. Remote Sensing of Environment 91(2):256-270

Xiao X, Zhang Q, Hollinger D, Aber J, Moore B III (2005) Modeling gross primary production of an evergreen needleleaf forest using MODIS and climate data. Ecological Applications 15(3):954-969

Xu X, Sherry RA, Niu S, Li D, Luo Y (2013) Net primary productivity and rain-use efficiency as affected by warming, altered precipitation, and clipping in a mixed-grass prairie. Glob Chang Biol 19(9):2753-2764

Yepez EA, Scott RL, Cable WL, Williams DG (2007) Intraseasonal variation in water and carbon dioxide flux components in a semiarid riparian woodland. Ecosystems 10(7):1100-1115

Zhang L, Fan J, Zhang W, Tang F (2014) Impact of the Being and Tianjin Sand Source Control Project on the grassland soil organic carbon storage. Chinese Journal of Applied Ecology 25(2):374-380

Zur B, Jones J (1984) Diurnal changes in the instantaneous water use efficiency of a soybean crop. Agric For Meteorol 33(1):41-51 